\title{
Cysteine Supplementation to Parenteral Nutrition Improves Red Blood Cell Glutathione Concentrations of Critically Ill Preterm Neonates
}

\author{
Oscar R. Herrera1,2*, Michael C. Storm1,2, Emma M. Tillman1,2, Richard A. Helms ${ }^{1,2,3}$ \\ ${ }^{1}$ Department of Clinical Pharmacy and Translational Science, University of Tennessee Health Science Center, Memphis, USA \\ ${ }^{2}$ State of Tennessee Center for Pediatric Experimental Therapeutics, Memphis, USA \\ ${ }^{3}$ Department of Pediatrics, University of Tennessee Health Science Center, Memphis, USA \\ Email: *oherrera@uthsc.edu
}

How to cite this paper: Herrera, O.R., Storm, M.C., Tillman, E.M. and Helms, R.A. (2018) Cysteine Supplementation to $\mathrm{Pa}$ renteral Nutrition Improves Red Blood Cell Glutathione Concentrations of Critically Ill Preterm Neonates. Food and Nutrition Sciences, 9, 619-631.

https://doi.org/10.4236/fns.2018.95047

Received: March 11, 2018

Accepted: May 25, 2018

Published: May 28, 2018

Copyright (c) 2018 by authors and Scientific Research Publishing Inc. This work is licensed under the Creative Commons Attribution International License (CC BY 4.0).

http://creativecommons.org/licenses/by/4.0/

\begin{abstract}
Premature neonates have immature antioxidant enzyme systems rendering them more susceptible to oxidative injury. One key antioxidant is glutathione (GSH). The rate limiting amino acid (AA) in GSH production is thought to be cysteine. Critically ill premature neonates who are parenterally fed are often supplemented with additional cysteine, yet the need for cysteine and optimal dose is unknown. This was a prospective, un-blinded, three-group, randomized crossover study aimed to evaluate three doses of cysteine by analyzing red blood cell (RBC) GSH, plasma AA, weight, and nitrogen balance. Neonates were randomized to receive 72 hours of each of the following cysteine doses: $10 \mathrm{mg} / \mathrm{g} \mathrm{AA}, 20 \mathrm{mg} / \mathrm{g} \mathrm{AA}$, and $40 \mathrm{mg} / \mathrm{g} \mathrm{AA}$. GSH, plasma AAs, weight, and nitrogen balance were evaluated at baseline (after 72 hours of $0 \mathrm{mg} / \mathrm{g}$ AA), day three, day six, and day nine. Sixteen patients completed all doses of cysteine, which resulted in significantly increased RBC GSH concentrations over baseline. Plasma concentrations of cystine, total and free cysteine/cystine, glycine and serine increased with cysteine dose. All cysteine doses were associated with adequate weight gain, and positive nitrogen balance. These results are contrary to more recent studies of cysteine effect on RBC GSH concentrations in preterm neonates and infants, but may reflect the severity of illness in our study subjects, where cysteine requirements may be increased.
\end{abstract}

\section{Keywords}

Cysteine, Protein, Sulfur Amino Acid, Pediatric, Parenteral Nutrition, Septic 


\section{Introduction}

Preterm neonates are presumed to be deficient in the antioxidant glutathione (GSH) rendering them more susceptible to diseases associated with reactive oxygen species (ROS) including bronchopulmonary dysplasia (BPD), periventricular leukomalacia, and retinopathy of prematurity (ROP) [1]. Neonatal survivors of critical illness, exposed to ROS, often are affected by many health related complications causing long-term morbidity [2]. Therefore, lowering oxidative injury risk should be a priority for critically ill preterm neonates.

The amino acid (AA) cysteine comprises a third of the tri-peptide GSH and directly influences GSH production (Figure 1). Cysteine has been suggested to be a conditionally-essential AA for neonates, particularly in the preterm neonate. There have been multiple studies actively debating this issue [3] [4] [5]. The availability of cysteine is thought to be the rate limiting substrate for the synthesis of GSH [6] [7] [8] [9], though this has been questioned as well by investigators [10] [11]. Several previous studies in children with protein energy malnutrition (PEM) and human immunodeficiency virus (HIV) have demonstrated low RBC GSH concentrations that are responsive to acetylcysteine supplementation [7] [12]. A previous study in septic children found that whole blood GSH synthesis rates are reduced by $60 \%$ [13]. Most of the previous studies evaluating the requirement of cysteine and its effect on synthesis and concentration of red blood cell (RBC) GSH have been completed in stable preterm neonates and infants. Our main objective was to determine whether cysteine supplementation in critically ill, post-surgical neonates treated for surgeries influenced RBC GSH concentrations. The complexity of surgery/critical illness was estimated using the wound classifications as defined by the U.S Centers for Disease Control and Prevention (CDC): clean, clean contaminated, contaminated or dirty/infected [14].

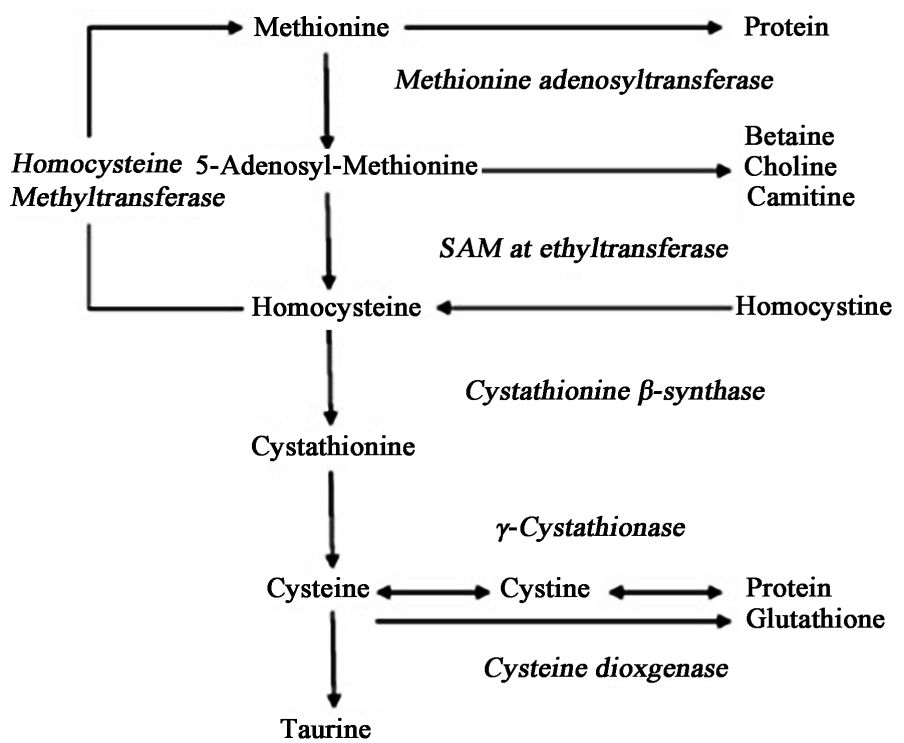

Figure 1. Transsulfuration pathway. 
Secondary objectives included the evaluation of plasma AAs, weight gain and nitrogen balance. Since this was designed as a short-term dose response study, weight gain and nitrogen balance were completed to ensure adequate nutrition across all study periods.

\section{Methods}

This was a prospective, randomized, single-center study assessing the effects of varying $\mathrm{L}$-cysteine $\mathrm{HCl}$ dosage in critically ill, post-surgical premature neonates who required parenteral nutrition (PN) support for at least two weeks between Fall 2011 and Spring 2012. Neonates with gestational age greater than 30 weeks but less than 37 weeks, and postnatal age less than 4 weeks were included in the study. Neonates were excluded from the study if they had any of the following major medical problems: inborn errors of metabolism, chromosomal abnormalities, end-stage liver or renal disease, peritoneal dialysis/hemofiltration, intraventricular hemorrhage (Grade IV), postnatal corticosteroid usage, extracorporeal membrane oxygenation (ECMO) support, or greater than $10 \%$ of nutritional goal as enteral intake. Institutional Review Board approval, and informed consent was obtained from the patient's parent or legal guardian prior to inclusion.

Post-surgical neonates were randomized in three groups based on a three-dose crossover design. All neonates received standard PN with the amino acid formulation TrophAmine 10\% (BBraun Medical, Bethlehem, PA), for 72 hours cysteine-free, followed by 72 hours of each cysteine dose $(10 \mathrm{mg}, 20 \mathrm{mg}$ and 40 mg cysteine per gram AA) in PN. The randomization schedule was based on a Latin square design as follows: neonates randomized to group 1 first received 10 $\mathrm{mg} / \mathrm{g}$ AA cysteine supplementation for three subsequent days. Similarly, neonates in groups 2 and 3 received $20 \mathrm{mg}$ or $40 \mathrm{mg} / \mathrm{g}$ AA cysteine supplementation for the same period. After 72 hours of supplementation, infants in each group were switched to a new dose and supplemented for an equal time. Doses were rotated per the randomized dosage scheme until all groups received all doses for 72 hours each. Steady-state AA concentrations were assessed after 72 hours of supplementation with the same cysteine dose [15]. Patient specific doses are shown in Table 1. Observations of intake and output, along with weights were recorded daily. Plasma AA and RBC GSH concentration were completed at day 0 (baseline), day 3, day 6, and day 9. Samples for analysis were coded for each subject without additional information about the protein dosage given at the time when collected. All neonates in this study received the standard PN regimen consisting of $2.5 \mathrm{~g} \mathrm{AA} / \mathrm{kg} /$ day with a $110 \mathrm{kcal} / \mathrm{kg} /$ day caloric goal. In addition to PN with standard dextrose concentrations, electrolytes, and minerals, carnitine was added at a dose of $10 \mathrm{mg} / \mathrm{kg} /$ day. No choline was added, although some choline would have been provided via the lipid product [16]. Nitrogen balance was calculated based on urine alone using total urinary nitrogen methodology [17]. Stool and gastric losses were not included, since output was minimal and only two patients were receiving minimal enteral nutrition. No correction factors were used to estimate insensible losses [18]. RBC GSH and plasma 
Table 1. Latin square design for cysteine dosing (mg/g AA).

\begin{tabular}{|c|c|c|c|c|}
\hline Subject & Baseline & Dose 1 & Dose 2 & Dose 3 \\
\hline 101 & 0 & 20 & 40 & 10 \\
\hline 102 & 0 & 10 & 40 & 20 \\
\hline 103 & 0 & 20 & 10 & 40 \\
\hline 104 & 0 & 10 & 20 & 40 \\
\hline 105 & 0 & 40 & 10 & 20 \\
\hline 106 & 0 & 40 & 20 & 10 \\
\hline 107 & 0 & 40 & 10 & 20 \\
\hline 108 & 0 & 10 & 40 & 20 \\
\hline 109 & 0 & 10 & 20 & 40 \\
\hline 110 & 0 & 20 & 10 & 40 \\
\hline 111 & 0 & 40 & 20 & 10 \\
\hline 112 & 0 & 20 & 40 & 10 \\
\hline 113 & 0 & 40 & 20 & 10 \\
\hline 114 & 0 & 20 & 10 & 40 \\
\hline 115 & 0 & 10 & 20 & 40 \\
\hline 116 & 0 & 20 & 40 & 10 \\
\hline 117 & 0 & 10 & 40 & 20 \\
\hline 118 & 0 & 40 & 10 & 20 \\
\hline 119 & 0 & 10 & 40 & 20 \\
\hline
\end{tabular}

AA analyses were performed on peripheral blood $(0.8 \mathrm{ml})$ collected in a separate heparinized tube at baseline and on the final day of each of the three different cysteine doses. Immediately after collection, blood samples were placed on ice and transported to the laboratory for separation of plasma within 30 minutes of collection. Samples were centrifuged for 15 minutes at 1800 times gravity, and whole plasma and packed erythrocytes collected for further analytical procedures. A portion of whole plasma was deproteinated with 5'-sulfosalicylic acid at $40 \mathrm{mg} / \mathrm{ml}$ plasma. Whole and deproteinated plasma were stored at $-70^{\circ} \mathrm{C}$ until further analyses. Packed RBCs were twice washed with normal saline and centrifuged. The final RBC pellet was re-suspended with an equal volume of double-distilled water, and vortexed vigorously. This RBC lysate was quickly frozen and thawed twice, and then centrifuged at 13,000 rpm for 10 minutes. The lysed RBC supernatant was then frozen at $-70^{\circ} \mathrm{C}$. Free AA concentrations in deproteinated plasma were measured on a Beckman 6300 AA analyzer using a $10 \mathrm{~cm} \mathrm{Li} \mathrm{high} \mathrm{performance} \mathrm{column,} \mathrm{four} \mathrm{lithium} \mathrm{citrate} \mathrm{buffers,} \mathrm{and} \mathrm{an} \mathrm{ex-}$ panded physiological sample program. The AA analyzer only measures cystine, and has an accuracy of $\pm 7 \%$. Total and free cysteine/cystine concentrations in whole plasma were measured spectrophotometrically by the method of Gaitonde as modified by Malloy [19] [20]. This method uses the reducing agent dithioth- 
reitol for sample conversion of total and free cysteine/cystine to cysteine, followed by a reaction with ninhydrin reagent. Total and free cysteine/cystine has a reported assay accuracy of $\pm 5 \%$. The conjugate, D-glucose-L-cysteine, cannot be distinguished from total and free cysteine/cystine by this method, but was assumed to be of small importance to our analyses. Thus, we report plasma cystine, and plasma total and free cysteine/cystine, similar to previous reports [21] [22] [23] [24]. RBC total GSH on lysed RBC samples was analyzed using the Tietze enzymatic method (Bioxytech GSH/GSSG-412, Oxis Health Products, Portland, OR) [25]. This method measures both GSH and reduced GSH (GSSG) in the lysed RBC sample. In this study, results are reported as total RBC GSH. Baseline demographic characteristics, intake totals with respect to calories, total protein and specific amino acids, as well as, blood concentrations of specific amino acids were described as means with standard error where appropriate. Statistical analyses of variables were performed on SPSS 32-bit software package for Windows (release 22.0.0; IBM Corp.).

\section{Results and Discussion}

Nineteen subjects were enrolled. Three subjects did not complete all dosage periods, and were excluded from analyses. Two subjects were able to rapidly advance to enteral feeds after one cysteine dosage period (patients 108, 113), and one subject expired during the first cysteine dosage period for reasons not related to the study (patient 110). Sixteen patients completed baseline, and all three cysteine doses. Demographic data are summarized in Table 2. Diagnoses are shown in Table 3.

\subsection{Intake}

Total calorie and protein doses were not significantly different during baseline and the 3 cysteine dosage periods. PN intake of the other sulfur AAs (methionine and taurine) were not significantly different across all study periods. Only

Table 2. Demographic data.

\begin{tabular}{cc}
\hline Characteristic & Mean \pm SEM \\
\hline Birth Weight (g) & $2469 \pm 144$ \\
Baseline Weight (g) & $2615 \pm 149$ \\
Length (cm) & $46.3 \pm 1.42$ \\
Gestational Age (weeks) & $36.3 \pm 0.493$ \\
Postnatal age (days) & $6.25 \pm 1.16$ \\
Race (n = 16) & 7 \\
Caucasian & 9 \\
African-American & \\
Sex (n = 16) & 9 \\
Male & 7 \\
Female & \\
\hline
\end{tabular}

Mean values reported with standard error of the mean (SEM). 
Table 3. Patient diagnoses.

\begin{tabular}{cccc}
\hline Patient & Primary Diagnosis & Secondary Diagnosis & Wound Classification \\
\hline 101 & Gastroschisis & Small bowel obstruction & Dirty \\
102 & Gastroschisis & None & Dirty \\
103 & Esophageal Atresia & NEC & Dirty \\
104 & Gastroschisis and Jejunal Atresia & SBS & Dirty \\
105 & TEF & Esophageal atresia & Clean \\
106 & Gastroschisis & None & Contaminated \\
107 & Gastroschisis & None & Contaminated \\
108 & Gastroschisis & None & Contaminated \\
109 & CDH & None & Clean-contaminated \\
110 & Esophageal Atresia & TEF & Clean \\
111 & Gastroschisis & Ileal Atresia & Contaminated \\
112 & Perforated NEC & BPD & Dirty \\
113 & Duodenal Atresia & None & Clean-contaminated \\
114 & Jejunal Atresia & None & Clean-contaminated \\
115 & Gastroschisis & NEC & Dirty \\
116 & CDH & None & Clean contaminated \\
117 & Gastroschisis & None & Contaminated \\
118 & Gastroschisis & None & Contaminated \\
119 & Gastroschisis & None & Contaminated \\
\hline
\end{tabular}

Bronchopulmonary Dysplasia, BPD; Congenital Diaphragmatic Hernia, CDH; Necrotizing Enterocolitis, NEC; Short Bowel Syndrome, SBS; Tracheo-esophageal fistula, TEF.

two subjects received minimal amounts of breast milk or infant formula during the last study period, but this amount was negligible (less than $10 \%$ of intake), therefore enteral intake was not included in total calorie or protein intake. Intake data are described on Table 4.

\subsection{Erythrocyte Glutathione}

RBC GSH concentrations at baseline (zero cysteine dose) were found to be 781 $\mu \mathrm{mol} / \mathrm{L}$ of packed RBCs in this group of 16 infants. At cysteine doses of 10, 20, and $40 \mathrm{mg} / \mathrm{g} \mathrm{AA}$, the resulting RBC GSH concentrations were 735, 903, and 1203 $\mu \mathrm{mol} / \mathrm{L}$ respectively. $\mathrm{RBC}$ total GSH concentrations were significantly higher at the 20 and $40 \mathrm{mg}$ cysteine dose compared to the 0 dose $(\mathrm{p}<0.05)$. In addition, the 20 and $40 \mathrm{mg}$ doses were significantly different from each other. Thus, there appeared to be a dose response of RBC total GSH to cysteine dose.

Baseline (zero cysteine dose) concentrations of RBC total GSH were highly variable. Thus, RBC GSH concentrations were evaluated by normalizing them to the baseline value and expressing each patient's result as a percent of baseline. On this basis, the results at the 10,20 , and $40 \mathrm{mg} / \mathrm{g}$ AA doses were $127 \% \pm$ $25.4 \%, 153 \% \pm 22.2 \%$, and $212 \% \pm 35.7 \%$, respectively. Again, the RBC GSH percentages above baseline at the 20 and 40 dose were significantly higher than at baseline ( $\mathrm{p}=0.002$ and 0.003 respectively) (See Table 4 ). 
Table 4. Results with escalating cysteine dose.

\begin{tabular}{|c|c|c|c|c|c|}
\hline & $\begin{array}{c}\text { Baseline } \\
\text { (no cysteine) }\end{array}$ & $\begin{array}{l}\text { Cysteine } \\
10 \mathrm{mg} / \mathrm{g} \mathrm{AA}\end{array}$ & $\begin{array}{c}\text { Cysteine } \\
20 \mathrm{mg} / \mathrm{g} \mathrm{AA}\end{array}$ & $\begin{array}{c}\text { Cysteine } \\
40 \mathrm{mg} / \mathrm{g} \mathrm{AA}\end{array}$ & $\begin{array}{c}\text { Breast fed } \\
\text { Infants [22] }\end{array}$ \\
\hline \multicolumn{6}{|l|}{ Total Intake } \\
\hline Calories (kcal/kg/day) & $92.6 \pm 13.7$ & $99.8 \pm 24.1$ & $99.9 \pm 15.8$ & $103.9 \pm 18.56$ & - \\
\hline Protein (g/kg/day) & $2.5 \pm 0.22$ & $2.5 \pm 0.31$ & $2.4 \pm 0.29$ & $2.4 \pm 0.33$ & - \\
\hline \multicolumn{6}{|l|}{ Sulfur Amino Acid Intake } \\
\hline Methionine (mg/kg/day) & $84.5 \pm 7.42$ & $83.5 \pm 10.7$ & $80.8 \pm 10.0$ & $82.8 \pm 11.3$ & - \\
\hline Cysteine (mg/kg/day) & - & $24.6 \pm 3.14 \dagger$ & $47.5 \pm 5.90 \dagger$ & $97.4 \pm 13.3 \dagger$ & - \\
\hline Taurine (mg/kg/day) & $6.2 \pm 0.60$ & $6.1 \pm 0.80$ & $5.9 \pm 0.80$ & $6.1 \pm 0.90$ & - \\
\hline Total Sulfur AA (mg/kg/day) & $90.8 \pm 8.20$ & $114.2 \pm 15.10$ & $125.9 \pm 37.50$ & $186.2 \pm 26.30$ & - \\
\hline \multicolumn{6}{|l|}{ Blood Concentrations } \\
\hline $\mathrm{RBC}$ GSH $(\mu \mathrm{mol} / \mathrm{L})$ & $781 \pm 122$ & $735 \pm 93.5$ & $903 \pm 118^{*}$ & $1203 \pm 124^{*} \dagger$ & - \\
\hline $\begin{array}{c}\text { GSH } \\
\text { (normalized as \% baseline) }\end{array}$ & 100 & $127 \pm 25.4$ & $153 \pm 22.2^{\star}$ & $212 \pm 35.7^{*} \dagger$ & - \\
\hline $\mathrm{Tau}(\mu \mathrm{mol} / \mathrm{L})$ & $38.2 \pm 23.2$ & $60.1 \pm 8.26^{*}$ & $54.9 \pm 5.08^{*}$ & $59.5 \pm 6.68^{*}$ & $83.9 \pm 9.72$ \\
\hline $\operatorname{Met}(\mu \mathrm{mol} / \mathrm{L})$ & $54.4 \pm 3.36$ & $52.3 \pm 2.60$ & $53.9 \pm 3.99$ & $57.4 \pm 3.78$ & $35.8 \pm 1.68$ \\
\hline Cys $(\mu \mathrm{mol} / \mathrm{L})$ & $35.1 \pm 3.54$ & $38.4 \pm 3.91$ & $46.3 \pm 3.65^{\star}$ & $50.3 \pm 6.27^{\star}$ & $51.9 \pm 2.00$ \\
\hline Gly $(\mu \mathrm{mol} / \mathrm{L})$ & $270 \pm 21.3$ & $299 \pm 21.1$ & $343 \pm 28.7^{\star}$ & $323 \pm 20.3^{*}$ & $226 \pm 17.6$ \\
\hline $\operatorname{Ser}(\mu \mathrm{mol} / \mathrm{L})$ & $117 \pm 8.07$ & $123 \pm 6.08$ & $137 \pm 9.64^{*}$ & $132 \pm 7.48^{\star}$ & $159 \pm 19.6$ \\
\hline Glu $(\mu \mathrm{mol} / \mathrm{L})$ & $52.9 \pm 7.45$ & $45.8 \pm 6.72$ & $48.9 \pm 5.67$ & $55.2 \pm 6.32$ & $134 \pm 12.8$ \\
\hline $\mathrm{Gln}(\mu \mathrm{mol} / \mathrm{L})$ & $390 \pm 30.9$ & $427 \pm 32$ & $461 \pm 23.2$ & $400 \pm 13.8$ & $496 \pm 41.6$ \\
\hline Total $[$ Cys + CysH] $(\mu \mathrm{mol} / \mathrm{L})$ & $136 \pm 9.79$ & $188 \pm 13.8^{*}$ & $206 \pm 14.0^{*}$ & $252 \pm 17.2^{\star} \dagger$ & $153.4 \pm 6.380$ \\
\hline \multicolumn{6}{|l|}{ Nutritional Assessments } \\
\hline Weight gain (g/day) & $10.3 \pm 5.60$ & $19.2 \pm 11.6$ & $29.8 \pm 12.8$ & $37.9 \pm 14.4$ & - \\
\hline Nitrogen balance (mg/kg/day) & $270 \pm 31.8$ & $294 \pm 31.3$ & $270 \pm 31.4$ & $321 \pm 26.8$ & - \\
\hline
\end{tabular}

Values are reported as mean \pm SEM. Statistical significance was set as $\mathrm{p}<0.05$. $\left.{ }^{*}\right]$ denotes statistically significant from baseline. $[\dagger]$ denotes statistically significant from other doses.

We sequentially evaluated cysteine dose effect on RBC GSH concentrations, plasma AA concentrations, growth, and nitrogen balance in critically ill, post-surgical preterm neonates. We did this using a randomized, Latin square design to minimize maturational effects that might occur over the 12 days of the study. No significant differences in weight gain were observed in the participants across the different cysteine dosage regimens. Weight gain, especially in the early days of the study, was likely confounded by increased fluid intake associated with surgeries. We found dose-dependent increases in RBC GSH, cystine, total cysteine/cystine, and taurine, but little additional effect on nitrogen balance with advancing dose. Such values are well below the range for adult RBC glutathione concentrations, GSH-repleted children with protein calorie malnutrition (PEM), and preterm infants. GSH concentrations were approximately 1500 to 2500 
$\mu \mathrm{mol} / \mathrm{L}$ [7] [10] [11]. Thus, our subjects appeared to have an initial relative deficiency in RBC GSH. At the $40 \mathrm{mg} /$ gram protein dose, RBC glutathione concentrations were roughly $60 \%$ of teBraake et al. reported GSH concentrations in stable preterm infants.

A number of recent studies have suggested cysteine has little to no effect on RBC GSH production in neonates [10] [11]. Furthermore, investigators have argued that low birth weight neonates and infants are capable of converting methionine to cysteine [3] [4] [26], relegating cysteine as non-essential as it is in healthy adults. We speculate that our results differ because cysteine, in critically-ill neonates, emerges as an acquired, indispensable AA [27]. Certainly, it has been shown that cysteine supplementation increases cystine, total cysteine/cystine, and taurine concentrations, suggesting a requirement for cysteine in PN formulation [18] [21] [28]. As an acquired indispensable AA, cysteine need is increased beyond the neonate's ability to synthesize under the conditions of severe disease and metabolic stress. Certainly in other metabolically stressed pediatric populations, cysteine supplementation has restored RBC and whole blood GSH concentrations [7], as well as in adults [29]. Our results suggest that significantly higher GSH concentrations are achieved with increasing cysteine supplementation. While the $10 \mathrm{mg} / \mathrm{g}$ AA dose had no effect, both the 20 and 40 $\mathrm{mg} / \mathrm{g}$ AA doses resulted in statistically significant improvements in RBC GSH concentrations (903 and $1203 \mu \mathrm{mol} / \mathrm{L}$ respectively). Nonetheless, after 3 days at our institution's normal PN dose for cysteine supplementation $(40 \mathrm{mg} / \mathrm{g} \mathrm{AA}$, or approximately $100 \mathrm{mg} / \mathrm{kg} /$ day), RBC GSH concentrations remained on average at approximately $50 \%$ of normal adult concentrations. This is in contrast to results described by Courtney-Martin et al. in neonates, where RBC GSH was not affected by supplementation of $10 \mathrm{mg} / \mathrm{kg}$ cysteine in a small study of five neonates [11]. However, even in the absence of cysteine supplementation at baseline, their subjects' RBC GSH concentrations were well above $2000 \mu \mathrm{mol} / \mathrm{L}$, and seem likely a reflection of how stable these infants were at the time of study. Our results reflect the effect of prior oxidative influences as a result of critical illness, and metabolic stress.

Critical illness and duration of oxidative stress may explain differences between our study and others. Sepsis has been shown to have deleterious effects in the concentrations of sulfur-containing amino acids, including cysteine, in both children and adults [13] [30]. teBraake et al. normal cysteine dose was described as $45 \mathrm{mg} / \mathrm{kg} / \mathrm{day}$, and high dose as $81 \mathrm{mg} / \mathrm{kg} /$ day. This high dose is about $80 \%$ of the highest dose used in our current study, nearly equal to the intake requirements of $77 \mathrm{mg} / \mathrm{kg} /$ day suggested by Snyderman [31] and 50\% - 60\% of the cysteine dose predicted in experiments by Heird et al. [32]. teBraake assessed $\mathrm{RBC}$ glutathione only once, at day 2 , in what were described as stable patients at normal and high doses of cysteine. No differences were observed in RBC GSH at either dose. For both cysteine dosing groups, their RBC GSH concentrations were in the range of 1800 to $2100 \mu \mathrm{mol} / \mathrm{L}$, well above our study findings regardless of cysteine dose. We chose to assess glutathione sequentially as cysteine dose 
was changed over 12 days. We expected the longer duration would be more reflective of RBC GSH status in critically-ill, post-surgical neonates. We chose 72-hour intervals based on previous studies that demonstrated steady-state amino acid concentrations being achieved in pediatric patients and exceeded the duration for most stable isotope studies evaluating GSH synthesis and RBC concentrations [15]. Regardless, RBC GSH improved with increases in cysteine dose, but did not correct to the values in studies of more stable neonates. We used diagnoses and wound classification as defined by the CDC to estimate the degree of critical illness post-operatively. We evaluated the effect of each wound class and cysteine dose on changes in cysteine concentrations from baseline. This yielded no statistically significant differences, though the $20 \mathrm{mg}$ dose trended towards significance, in large part due to the small sample size for each wound classification. Again, it leads us to speculate that there may be a range or trigger condition that creates a transient requirement for cysteine warranting further investigation with a larger patient set.

\subsection{Plasma Amino Acids}

In general, concentrations of plasma amino acids were not expected to vary during the course of the study since the only difference in each study period was cysteine dose.

Differences in plasma amino acids with cysteine dose were observed in the sulfur containing amino acids. Table 4 summarizes these differences and also includes other amino acids involved in glutathione synthesis. The plasma concentration of free cystine increased with increasing cysteine dosage in an apparent dose dependent manner. The values were $35.1,38.4,46.3$, and $50.3 \mu \mathrm{mol} / \mathrm{L}$ for the zero, 10, 20, and $40 \mathrm{mg} / \mathrm{g} \mathrm{AA}$, respectively. The normal concentration for breast-fed term neonates is $35-69 \mu \mathrm{mol} / \mathrm{L}$. The concentration at $40 \mathrm{mg} / \mathrm{g} \mathrm{AA}$ dose was significantly higher than the value at zero cysteine dose $(\mathrm{p}=0.021)$ and the $10 \mathrm{mg} / \mathrm{g}$ AA dose $(\mathrm{p}=0.003)$. Similarly, plasma concentrations of total and free cysteine/cystine increased with increasing cysteine dose. These were 136, 188,206 , and $252 \mu \mathrm{mol} / \mathrm{L}$ for the zero, 10,20 , and $40 \mathrm{mg} / \mathrm{g} \mathrm{AA}$, respectively. The normal concentration range for breast-fed term neonates is $99-208 \mu \mathrm{mol} / \mathrm{L}$ [22]. All doses of cysteine produced significant increases in total and free cysteine/cystine compared to the zero cysteine dose (see Table 4). The plasma concentrations of taurine also increased with cysteine supplementation. These were $38.2,60.1,54.9$, and $59.5 \mu \mathrm{mol} / \mathrm{L}$ at the $0,10,20$, and $40 \mathrm{mg} / \mathrm{g}$ AA doses respectively. The result at all doses of cysteine were significantly different from the zero dose $(\mathrm{p}<0.05)$, but there were no significant differences among the three doses in plasma taurine concentrations. In breast-fed term infants, normal taurine concentrations ranged from $10-167 \mu \mathrm{mol} / \mathrm{L}$. In this study, plasma methionine concentrations did not differ with cysteine dose; they were 54.4, 52.3, 53.9, and $57.4 \mu \mathrm{mol} / \mathrm{L}$ at the $0,10,20$, and $40 \mathrm{mg} / \mathrm{g}$ AA doses respectively. Similarly, plasma glutamic acid concentrations and plasma glutamine concentrations did not vary with cysteine dose (see Table 4). There were apparent differences in plasma 
concentrations of both glycine and serine with cysteine dose. These were 270, 299,343 , and $323 \mu \mathrm{mol} / \mathrm{L}$ at the $0,10,20$, and $40 \mathrm{mg} / \mathrm{g}$ AA cysteine doses respectively. The concentrations at 20 and 40 were significantly higher than at the zero cysteine dose. There were no differences in plasma glycine concentration among the 3 cysteine doses. The results for plasma serine were similar. The concentrations were $117,123,137,132 \mu \mathrm{mol} / \mathrm{L}$ at the zero, 10,20 , and $40 \mathrm{mg} / \mathrm{g}$ AA cysteine doses respectively. Again, concentrations at the 20 and $40 \mathrm{mg}$ dose were significantly higher than the zero dose; there were no significant difference among plasma serine concentrations for the 3 cysteine doses. In term breast-fed infants, glycine concentrations are $77-376 \mu \mathrm{mol} / \mathrm{L}$ and serine concentrations are 0 - 326 $\mu \mathrm{mol} / \mathrm{L}[22]$.

As for other amino acids, plasma concentrations of taurine (Figure 1) also increased with cysteine dose. However, there was no dose dependent nature to this increase suggesting that this may have been limited by maturational events related to enzymes of the trans-sulfuration pathway. All subsequent plasma concentrations were improved compared to the baseline observation and there was no significant difference with respect to cysteine dose. Since infants received the same amount of taurine in PN during all study periods, the apparent increase may have been a time on PN-dependent event. Alternatively, a minimal amount of cysteine $(10 \mathrm{mg} / \mathrm{g} \mathrm{AA})$ in PN may be sufficient to increase plasma taurine concentrations versus no added cysteine. Since the range of normal plasma concentrations for taurine are so large $(1-167 \mu \mathrm{mol} / \mathrm{L})$ [22], even the plasma taurine concentrations in the absence of cysteine supplementation $(38.2 \mu \mathrm{mol} / \mathrm{L})$ could be considered normal. However, the normal mean taurine concentration is $83.9 \mu \mathrm{mol} / \mathrm{L}$. Studies by Meister et al. showed that administration of high doses of cysteine does not increase cellular GSH as expected due to feedback inhibition of $\gamma$-glutamylcysteinesynthetase by glutathione [33]. Another possible explanation is that doses above $40 \mathrm{mg} / \mathrm{g}$ AA may be required to adequately detect this dose response in GSH and taurine concentrations.

A somewhat surprising observation was the modest, but statistically significant, increase in both plasma glycine and plasma serine concentrations with increasing cysteine dose. No such effect was observed when the plasma amino acid concentrations were observed from a temporal basis. Glycine is a direct component of the tripeptide glutathione ( $\gamma$-glutamyl-cysteinyl-glycine). Perhaps, with an increase in available intracellular cysteine, less intracellular glycine is required and there is a concomitant increase in plasma glycine concentrations.

\subsection{Weight Gain and Nitrogen Balance}

Change in weight was evaluated by tracking weight recorded in the medical record for each study day. Infants gained weight during the course of the 12-day study at a rate of $12 \pm 3 \mathrm{~g} / \mathrm{kg} / \mathrm{d}$. Weight change was also evaluated during each of the 3-day study periods. There was no statistically significant change in weight gain across any study period. Nitrogen balance was determined during the last 24-hour period of each study period. The results were 270, 294, 270, and 321 
$\mathrm{mg} / \mathrm{kg} / \mathrm{d}$ for the zero, 10,20 , and $40 \mathrm{mg} / \mathrm{g}$ AA doses, respectively. While there is a slight trend to increasing nitrogen balance with increasing cysteine dose in this short-term study, there are no statistically significant differences among any of these values. The difference between zero dose $(270 \mathrm{mg} / \mathrm{kg} / \mathrm{d})$ and the $40 \mathrm{mg}$ dose $(321 \mathrm{mg} / \mathrm{kg} / \mathrm{d})$ was approximately $51 \mathrm{mg} / \mathrm{kg} / \mathrm{d}$. However, due to the small study population, this only trended toward statistical significance $(\mathrm{p}=0.058)$.

\section{Conclusion}

In summary, we found dose-dependent increases in RBC GSH with increasing doses of cysteine. Our total sulfur amino acid intake and requirement for cysteine supplementation, above $10 \mathrm{mg} / \mathrm{kg} /$ day, exceeds that predicted by other studies in term, stable infants. Whether cysteine is a conditionally-essential amino acid for all neonates is up for debate; however, it appears that prematurity and sepsis/critical illness predisposes these patients to increase requirements that may warrant supplementation. The Latin square design, longitudinal assessment of RBC GSH, and metabolically relevant amino acid findings are strengths of the current study, and likely suggest additional studies are required to better understand cysteine dosing in neonates and infants experiencing the metabolic stress of critical illness.

\section{Acknowledgements}

Funding for this study was obtained from an unrestricted grant through the Center for Pediatric Experimental Therapeutics. Dr. Michael Storm and Dr. Emma Tillman had appointments within the UTHSC College of Pharmacy and the CPET when the project was initiated. Dr. Storm has since retired and Dr. Tillman is currently a clinical pharmacist at Riley Children's Hospital.

\section{References}

[1] Auten, R.L. and Davis, J.M. (2009) Oxygen Toxicity and Reactive Oxygen Species: The Devil Is in the Details. Pediatric Research, 66, 121-127. https://doi.org/10.1203/PDR.0b013e3181a9eafb

[2] Sola, A., Rogido, M.R. and Deulofeut, R. (2007) Oxygen as a Neonatal Health Hazard: Call for Detente in Clinical Practice. Actapaediatrica, 96, 801-812. https://doi.org/10.1111/j.1651-2227.2007.00287.x

[3] Shew, S.B., Keshen, T.H., Jahoor, F. and Jaksic, T. (2005) Assessment of Cysteine Synthesis in Very Low-Birth Weight Neonates Using a $\left[{ }^{13} \mathrm{C}_{6}\right]$ Glucose Tracer. Journal of Pediatric Surgery, 40, 52-56. https://doi.org/10.1016/j.jpedsurg.2004.09.011

[4] Courtney-Martin, G., Chapman, K.P., Moore, A.M., Kim, J.H., Ball, R.O. and Pencharz, P.B. (2008) Total Sulfur Amino Acid Requirement and Metabolism in Parenterally Fed Postsurgical Human Neonates. The American Journal of Clinical Nutrition, 88, 115-124. https://doi.org/10.1093/ajcn/88.1.115

[5] Riedijk, M.A., Voortman, G., van Beek, R.H., Baartmans, M.G., Wafelman, L.S. and van Goudoever, J.B. (2008) Cyst(e)ine Requirements in Enterally Fed Very Low Birth Weight Preterm Infants. Pediatrics, 121, e561-e567.

https://doi.org/10.1542/peds.2007-0494 
[6] Borum, P. and Rowe, W. (1992) Procysteine Supplemented TPN Increases Glutathione and Cysteine Concentrations in Cardiac Tissue of Neonatal Piglets. The American Journal of Clinical Nutrition, 56, 757.

[7] Badaloo, A., Reid, M., Forrester, T., Heird, W.C. and Jahoor, F. (2002) Cysteine Supplementation Improves the Erythrocyte Glutathione Synthesis Rate in Children with Severe Edematous Malnutrition. The American Journal of Clinical Nutrition, 76, 646-652. https://doi.org/10.1093/ajcn/76.3.646

[8] Jahoor, F., Badaloo, A., Reid, M. and Forrester, T. (2006) Sulfur Amino Acid Metabolism in Children with Severe Childhood Undernutrition: Cysteine Kinetics. The American Journal of Clinical Nutrition, 84, 1393-1399. https://doi.org/10.1093/ajcn/84.6.1393

[9] Reid, M. and Jahoor, F. (2000) Methods for Measuring Glutathione Concentration and Rate of Synthesis. Current Opinion in Clinical Nutrition and Metabolic Care, 3 , 385-390. https://doi.org/10.1097/00075197-200009000-00010

[10] teBraake, F.W., Schierbeek, H., Vermes, A., Huijmans, J.G. and van Goudoever, J.B. (2009) High-Dose Cysteine Administration Does Not Increase Synthesis of the Antioxidant Glutathione Preterm Infants. Pediatrics, 124, e978-e984.

https://doi.org/10.1542/peds.2008-2477

[11] Courtney-Martin, G., Moore, A.M., Ball, R.O. and Pencharz, P.B. (2010) The Addition of Cysteine to the Total Sulphur Amino Acid Requirement as Methionine Does Not Increase Erythrocytes Glutathione Synthesis in the Parenterally Fed Human Neonate. Pediatric Research, 67, 320-324. https://doi.org/10.1203/PDR.0b013e3181ca036f

[12] Jahoor, F., Jackson, A., Gazzard, B., et al. (1999) Erythrocyte Glutathione Deficiency in Symptom-Free HIV Infection Is Associated with Decreased Synthesis Rate. The American Journal of Physiology, 276, E205-E211. https://doi.org/10.1152/ajpendo.1999.276.1.E205

[13] Lyons, J., Rauh-Pfeiffer, A., Ming-Yu, Y., et al. (2001) Cysteine Metabolism and Whole Blood Glutathione Synthesis in Septic Pediatric Patients. Critical Care Medicine, 29, 870-877. https://doi.org/10.1097/00003246-200104000-00036

[14] Berrios-Torres, S.I., Umscheid, C.A., Bratzler, D.W., et al. (2017) Centers for Disease Control and Prevention Guideline for the Prevention of Surgical Site Infection, 2017. JAMA Surgery, 152, 784-791. https://doi.org/10.1001/jamasurg.2017.0904

[15] Winters, R.W., Heird, W.C. and Dell, R.B. (1977) Plasma Amino Acids in Infants Receiving Parenteral Nutrition. Paper presented at: Clinical Nutrition Update.

[16] Sheard, N.F., Tayek, J.A., Bistrian, B.R., Blackburn, G.L. and Zeisel, S.H. (1986) Plasma Choline Concentration in Humans Fed Parenterally. The American Journal of Clinical Nutrition, 43, 219-224. https://doi.org/10.1093/ajcn/43.2.219

[17] Boehm, K.A. (1994) Accuracy of Urinary Nitrogen for Predicting Total Urinary Nitrogen in Thermally Injured Patients. JPEN Journal of Parenteral and Enteral Nutrition, 18, 285-286. https://doi.org/10.1177/0148607194018003285

[18] Helms, R.A., Mowatt-Larssen, C.A., Boehm, K.A., et al. (1993) Urinary Nitrogen Constituents in the Postsurgical Preterm Neonate Receiving Parenteral Nutrition. JPEN Journal of Parenteral and Enteral Nutrition, 17, 68-72. https://doi.org/10.1177/014860719301700168

[19] Gaitonde, M.K. (1967) A Spectrophotometric Method for the Direct Determination of Cysteine in the Presence of Other Naturally Occurring Amino Acids. Biochemical Journal, 104, 627-633. https://doi.org/10.1042/bj1040627

[20] Malloy, M.H., Rassin, D.K. and Gaull, G.E. (1981) A Method for Measurement of 
Free and Bound Plasma Cyst(e)ine. Analytical Biochemistry, 113, 407-415. https://doi.org/10.1016/0003-2697(81)90095-6

[21] Helms, R.A., Christensen, M.L., Mauer, E.C. and Storm, M.C. (1987) Comparison of a Pediatric versus Standard Amino Acid Formulation in Preterm Neonates Requiring Parenteral Nutrition. The Journal of Pediatrics, 110, 466-470. https://doi.org/10.1016/S0022-3476(87)80519-X

[22] Wu, P.Y., Edwards, N. and Storm, M.C. (1986) Plasma Amino Acid Pattern in Normal Term Breast-Fed Infants. The Journal of Pediatrics, 109, 347-349. https://doi.org/10.1016/S0022-3476(86)80400-0

[23] Heird, W.C., Dell, R.B., Helms, R.A., et al. (1987) Amino Acid Mixture Designed to Maintain Normal Plasma Amino Acid Patterns in Infants and Children Requiring Parenteral Nutrition. Pediatrics, 80, 401-408.

[24] Heird, W.C., Hay, W., Helms, R.A., Storm, M.C., Kashyap, S. and Dell, R.B. (1988) Pediatric Parenteral Amino Acid Mixture in Low Birth Weight Infants. Pediatrics, 81, 41-50.

[25] Eady, J.J., Orta, T., Dennis, M.F., Stratford, M.R. and Peacock, J.H. (1995) Glutathione Determination by the Tietze Enzymatic Recycling Assay and Its Relationship to Cellular Radiation Response. British Journal of Cancer, 72, 1089-1095. https://doi.org/10.1038/bjc.1995.470

[26] Riedijk, M.A., van Beek, R.H., Voortman, G., de Bie, H.M., Dassel, A.C. and van Goudoever, J.B. (2007) Cysteine: A Conditionally Essential Amino Acid in Low-Birth-Weight Preterm Infants? The American Journal of Clinical Nutrition, 86, 1120-1125. https://doi.org/10.1093/ajcn/86.4.1120

[27] Laidlaw, S.A. and Kopple, J.D. (1987) Newer Concepts of the Indispensable Amino Acids. The American Journal of Clinical Nutrition, 46, 593-605.

https://doi.org/10.1093/ajcn/46.4.593

[28] Badaloo, A., Hsu, J.W., Taylor-Bryan, C., et al. (2012) Dietary Cysteine Is Used More Efficiently by Children with Severe Acute Malnutrition with Edema Compared with Those without Edema. The American Journal of Clinical Nutrition, 95, 84-90. https://doi.org/10.3945/ajcn.111.024323

[29] Borges-Santos, M.D., Moreto, F., Pereira, P.C., Ming-Yu, Y. and Burini, R.C. (2012) Plasma Glutathione of HIV(+) Patients Responded Positively and Differently to Dietary Supplementation with Cysteine or Glutamine. Nutrition, 28, 753-756. https://doi.org/10.1016/j.nut.2011.10.014

[30] Su, L., Li, H., Xie, A., et al. (2015) Dynamic Changes in Amino Acid Concentration Profiles in Patients with Sepsis. PLOS ONE, 10, e0121933. https://doi.org/10.1371/journal.pone.0121933

[31] Snyderman, S.E. (1971) The Protein and Amino Acid Requirements of the Premature Infant. In: Ionxix, J.H.P., Visser, H.K.A. and Troelstra, J.D., Eds., Metabolic Processes in the Fetus and Newborn Infant, HE StenfertKroesse, Nevada, 128-141. https://doi.org/10.1007/978-94-010-2951-3_9

[32] Heird, W.C., Dell, R.B. and Winters, R.W. (1982) Food and Metabolism in Infancy. The Relationships of Plasma Amino Acids as an Indicator of the Adequacy of Protein Intake. Acta Paediatrica Scandinavica. Supplement, 299, 24-32. https://doi.org/10.1111/j.1651-2227.1982.tb09623.x

[33] Meister, A. (1984) New Aspects of Glutathione Biochemistry and Transport-Selective Alteration of Glutathione Metabolism. Nutrition Reviews, 42, 397-410. https://doi.org/10.1111/j.1753-4887.1984.tb02277.x 